\title{
Past food habit change is related to obesity, lifestyle and socio-economic factors in the Malmo Diet and Cancer Cohort
}

\author{
Emily Sonestedt*, Elisabet Wirfält, Bo Gullberg and Göran Berglund \\ Department of Clinical Sciences, Lund University, Malmö University Hospital, Malmo Diet and Cancer, Entrance 59, \\ SE-205 02 Malmö, Sweden
}

Submitted 14 July 2004: Accepted 15 March 2005

\begin{abstract}
Objectives: To examine if obesity status and socio-economic and lifestyle factors are associated with self-reported past food habit change, and also whether the level of obesity depends on the reason for change.

Design: Cross-sectional analysis within the Malmo Diet and Cancer (MDC) study using data from the baseline examination and the extensive socio-economic and lifestyle questionnaire including questions of past food habit change. The risk of having changed food habits in the past was examined using logistic regression. Mean differences in obesity status across categories of reasons for past food habit change were examined using analysis of variance.

Setting: Malmö, the third largest city in Sweden.

Subjects: A sub-sample (15282 women and 9867 men) from the MDC cohort recruited from 1992 to 1996.

Results: Individuals with body mass index (BMI) $>30 \mathrm{~kg} \mathrm{~m}^{-2}$ had an increased risk of having reported past food habit change compared with individuals with BMI $<25 \mathrm{~kg} \mathrm{~m}^{-2}$ (odds ratio $(\mathrm{OR})=1.63,95 \%$ confidence interval $(\mathrm{CI})=1.48-1.83$ for women; $\mathrm{OR}=1.53,95 \% \mathrm{CI}=1.32-1.76$ for men). The highest level of obesity was observed among individuals who had changed their diet due to reasons related to the metabolic syndrome. Changers were more likely to be highly educated and to live alone, be retired, ex-smokers and non-drinkers at baseline.

Conclusions: Because past food habit change is related to obesity and other lifestyle and socio-economic factors, a complex confounding situation may exist that could seriously influence observed relationships between diet and disease. Studies need to collect information on past food habit change and take this information into account in the analysis and when interpreting study outcomes.
\end{abstract}

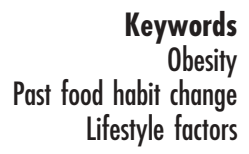

eywords

ifestyle factors
Chronic diseases, including cancer, are believed to have long latency periods ${ }^{1}$. In fact, dietary habits from a decade ago and those close to the presentation of the disease could both be of importance. Dietary habits are, however, relatively stable ${ }^{2}$ and the ability to change food habits varies between individuals ${ }^{3}$. Dietary changes over time may occur because active decisions are made about lifestyle and dietary behaviours ${ }^{4-6}$. Food habits may also change because the availability of food products changes $^{7-9}$, or because alterations in life circumstances force individuals to change $\mathrm{c}^{8,10}$. During the baseline examinations of the Malmo Diet and Cancer (MDC) study, some questions on past food habit change were asked in order to adjust in analysis for the most obvious dietary changes in the past. The information obtained included when the change occurred, the reasons for dietary change and how the diet had changed.

Previous cross-sectional analyses within the MDC study have indicated that individuals with higher body mass index (BMI) appear to have changed their diets in the past to a greater degree than individuals with normal $\mathrm{BMI}^{11}$. This observation is of specific concern, because body fatness is a well-known risk factor in chronic disease and cancer epidemiology ${ }^{12}$. Studies examining the relationships between diet and cancer need to separate out risks associated with body fatness from risks of specific dietary factors. The dietary habits before a lifestyle change may be positively related to body fatness and to the development of the disease $\mathrm{e}^{13}$, but the dietary habits after the change may have a different biological relationship. To clarify these relationships we now wish to examine more closely if obesity status depends on the specific reason for dietary change. Also, we wish to examine characteristics associated with past food habit change.

The specific aims of the present study were first to examine the risk of past diet change in relation to obesity status categories, while simultaneously evaluating the impact of socio-economic, demographic and lifestyle 
factors on this relationship. Secondly, the project examined mean differences in BMI across categories of reasons for food habit change, controlling for potential confounders.

\section{Material and methods}

\section{Population}

The MDC study, which is a population-based prospective cohort study in the third largest city of Sweden (250000 inhabitants), conducted baseline examinations from March 1991 to October 1996. All men, aged 50 to 73 years, and all women, aged 45 to 73 years, living in Malmö were invited to take part in the study. Lack of Swedish language skills was the only exclusion criterion. With a participation rate of approximately $40 \%$, the cohort consists of 28098 individuals who either joined the study spontaneously or after receiving a mail invitation. A more detailed description of the cohort is given elsewhere ${ }^{14,15}$

\section{Study sample}

Three different versions of the socio-economic and lifestyle questionnaire were used during the baseline examinations. Only the second and third versions had information for all variables examined in this project and therefore constitute the study sample in the present study (women $n=15282$; men $n=9867$ ). Version 2 was used during February 1992 to December 1994 and version 3 was used during December 1994 to December 1996.

\section{Past food babit change}

The independent variables used in this study are past food habit change and different reasons for past food habit change. Past food habit change was derived from the questionnaire item 'Have you substantially changed your eating habits because of illness or some other reasons?' and dichotomised into one variable as non-changers and changers. Subjects who reported change in diet were asked for the reasons for food habit change in closedended answer categories covering both health-related and more general reasons.

- Health reasons type one included: hypertension, high blood lipids, cardiovascular diseases, overweight, diabetes, high blood sugar, less physically active and a wish to control body weight. The classification was based on the assumption that these individuals might have similar food habits because they have received similar type of advice for diet change.

- Health reasons type two included: more physically active, allergy, gastrointestinal disorder and mental disorder. These reasons for change are not associated with any obvious dietary pattern similarities.

- Non-health reasons included: changed working hours, physically heavier work, eat alone nowadays, unemployment, physically lighter work, eat in company of others nowadays, worsened economy, retirement, disease in family, and other reasons.

A six-category variable was constructed discriminating among non-changers, diet changers for health reasons type one only, diet changers for health reasons type two only, diet changers with both types of health reasons, diet changers for non-health reasons only, and diet changers with both health and non-health reasons. The duration (time period) since food habit change was computed from the self-reported calendar year when respondents had changed their diet and the date for the baseline examinations.

\section{Obesity}

Trained project staff measured weights, heights, waist (midway between the lowest rib margin and the iliac crest) and hip circumferences (horizontally at the level of greatest lateral extension of hips) during baseline examinations with subjects in light indoor clothing and without shoes. $B M I\left(\mathrm{~kg} \mathrm{~m}^{-2}\right)$ was defined as weight $(\mathrm{kg})$ divided by the square of height $(\mathrm{m})$. A three-category BMI variable was created, with subjects categorised as normal weight $\left(<25 \mathrm{~kg} \mathrm{~m}^{-2}\right)$, overweight $\left(25-29 \mathrm{~kg} \mathrm{~m}^{-2}\right)$ or obese $\left(\geq 30 \mathrm{~kg} \mathrm{~m}^{-2}\right)$ according to the classification of the World Health Organization ${ }^{16}$. Central obesity was defined as a waist circumference larger than $94 \mathrm{~cm}$ for men and $80 \mathrm{~cm}$ for women ${ }^{17}$.

\section{Otber variables}

Information on age and gender was obtained through the person-identification number. Age was arranged in 5-year categories (i.e. $<50,50-54,55-59,60-64$ and $>65$ years).

Information on socio-economic, demographic and lifestyle factors was obtained through a standardised questionnaire.

- Education. A five-category variable was created defined by the type of education attained: elementary, primary and secondary, upper secondary, further education without a degree and university degree.

- Socio-economic status was defined according to the index commonly used by the National Bureau of Statistics, Sweden ${ }^{18}$. A three-category variable was created: blue-collar workers, white-collar workers, and self-employed and employers.

- Marital status was defined by a four-category variable (i.e. married, not married, divorced and widow/ widower).

- Co-babitation status was grouped into single living and co-living individuals (with adults and/or children).

- Country of birth. A two-category variable was created (i.e. born in Sweden vs. not born in Sweden) with individuals born in other countries merged into one single category. 
- The occupation variable was grouped into three categories: gainfully employed, retired and others (home workers, students and unemployed).

- Alcohol. The information on alcohol consumption was obtained from the socio-economic and lifestyle questionnaire and the dietary data collection, which is a modified diet history method specifically developed for the MDC study ${ }^{19}$. Individuals who reported zero consumption in the menu book, and who indicated in the socio-economic and lifestyle questionnaire that they had not consumed any alcohol during the previous year, were categorised as zero consumers. The other subjects were categorised according to an assumption of biological risk ${ }^{20}$. The categories for men/women were, respectively: $<20 \mathrm{~g} /<15 \mathrm{~g}$ alcohol daily (low), 20-40 g/15-30 g alcohol daily (medium), and $>40 \mathrm{~g} />30 \mathrm{~g}$ alcohol daily (high).

- Smoking status was defined by a three-category variable: current smokers (including irregular smokers), ex-smokers and never smokers.

- Leisure-time physical activity was assessed by a list of activities in the questionnaire (18 items). Participants were asked to report how many minutes per week on average, and for each of the four seasons, they spend on a specific activity. These figures were all multiplied by an activity-specific factor. A physical activity score was obtained by computing the sum of all activity products. Four categories of leisure-time physical activity were identified by the participants' quartile ranking.

- Physical activity at work was defined by a four-category item in the questionnaire: very low, low, medium and high activity.

- Household work was assessed by the self-reported number of hours a week spent on household work, including shopping. A variable with four categories was constructed: $0-6$ h, $7-13$ h, 14-19h and $>20$ h weekly.

\section{Statistical analysis}

The SPSS statistical computer package (version 11.5; SPSS Inc., Chicago, IL, USA) was used for statistical analyses and all analyses were separated by gender. Differences at the 0.05 level were considered statistically significant. Bivariate analyses of different variables in relation to past food habit change were performed. The categorical variables examined were: education, socio-economic status, country of birth, occupation, marital status, co-habitation status, age at baseline (categorical), alcohol consumption, smoking habits, physical activity at work, physical activity at leisure time, household work, categories of BMI and central obesity status. Logistic regression was used to assess the risk of having changed the diet in the past in relation to different BMI categories, lifestyle and demographic characteristics. These characteristics were first analysed in separate models. Secondly, analysis was performed with all categorical variables in the same model, except waist circumference. Trend tests were performed for BMI, age, alcohol consumption, physical activity at leisure time, physical activity at work and household work. The risk of past food habit change for waist circumference categories was controlled for the potential confounders and BMI. Finally, analysis of variance compared the mean differences of BMI across the six categories of reasons for food habit change, controlling for potential confounders. Median time since change and 25 th, 75 th and 95 th percentiles for time since change across reasons for change were computed.

\section{Results}

\section{Participant characteristics}

Characteristics of the study population are described in Table 1. Approximately a quarter of the study population

Table 1 Characteristics of a sub-sample of women $(n=15282)$ and men $(n=9867)$ from the Malmo Diet and Cancer cohort

\begin{tabular}{|c|c|c|c|c|}
\hline & \multicolumn{2}{|c|}{ Women } & \multicolumn{2}{|c|}{ Men } \\
\hline & $n$ & $\%$ & $n$ & $\%$ \\
\hline \multicolumn{5}{|l|}{ Age (years) } \\
\hline$<50$ & 3853 & 25 & 926 & 9 \\
\hline $50-54$ & 2892 & 19 & 2289 & 23 \\
\hline $55-59$ & 2469 & 16 & 2014 & 20 \\
\hline $60-64$ & 2681 & 18 & 2083 & 21 \\
\hline$\geq 65$ & 3387 & 22 & 2555 & 26 \\
\hline Past food habit change & 3718 & 24 & 2231 & 23 \\
\hline \multicolumn{5}{|l|}{ Reasons for food habit change } \\
\hline Health reason type one & 1187 & $32^{*}$ & 967 & 44 \\
\hline Health reason type two & 332 & 9 & 138 & 6 \\
\hline Both types of health reasons & 390 & 11 & 177 & 8 \\
\hline Non-health reasons & 626 & 17 & 242 & 11 \\
\hline Both health and non-health reasons & 1185 & 32 & 694 & 31 \\
\hline \multicolumn{5}{|l|}{ Body mass index $\left(\mathrm{kg} \mathrm{m}^{-2}\right)$} \\
\hline$<25$ & 8006 & 53 & 3674 & 37 \\
\hline $25-29$ & 5136 & 34 & 4894 & 50 \\
\hline$\geq 30$ & 2114 & 14 & 1285 & 13 \\
\hline Central obesity & 4970 & 33 & 4255 & 43 \\
\hline \multicolumn{5}{|l|}{ Socio-economic status } \\
\hline Blue-collar worker & 5763 & 38 & 3547 & 36 \\
\hline White-collar worker & 8181 & 54 & 4555 & 46 \\
\hline Other & 1187 & 8 & 1727 & 18 \\
\hline \multicolumn{5}{|l|}{ Co-habitation status } \\
\hline Living alone & 4340 & 28 & 1862 & 19 \\
\hline \multicolumn{5}{|l|}{ Occupation } \\
\hline Retired & 5069 & 33 & 3730 & 38 \\
\hline Employed & 8838 & 58 & 5464 & 56 \\
\hline \multicolumn{5}{|l|}{ Marital status } \\
\hline Married & 9168 & 60 & 7109 & 72 \\
\hline Non-married & 1414 & 9 & 1008 & 10 \\
\hline Divorced & 3117 & 20 & 1411 & 14 \\
\hline Widow/widower & 1572 & 10 & 335 & 3 \\
\hline \multicolumn{5}{|l|}{ Education } \\
\hline Elementary & 5951 & 39 & 4529 & 46 \\
\hline University degree & 2271 & 15 & 1301 & 13 \\
\hline \multicolumn{5}{|l|}{ Country of birth } \\
\hline Sweden & 13426 & 88 & 8662 & 88 \\
\hline \multicolumn{5}{|l|}{ Smoking habit } \\
\hline Current smoker & 4340 & 28 & 2839 & 29 \\
\hline Ex-smoker & 4292 & 28 & 4263 & 43 \\
\hline Non-smoker & 6646 & 44 & 2760 & 28 \\
\hline \multicolumn{5}{|l|}{ Alcohol consumption } \\
\hline Non-drinker & 1173 & 8 & 442 & 5 \\
\hline
\end{tabular}

*Percentage of individuals reporting past food habit change. 
reported past change in food habits. The most commonly reported reasons for change in both men and women were health reasons type one, and a combination of both health and non-health reasons. Non-health reasons for change were more common among women than among men. The median time since past food habit change was 4 years for women and 5 years for men. The level of obesity was slightly different across gender groups. Similar proportions of women and men were obese (13-14\%). However, more females had BMI below $25 \mathrm{~kg} \mathrm{~m}^{-2}$. Females also had a lower degree of central obesity.

\section{Multivariate analyses for food habit change}

Tables 2 and 3 show the risk of past food habit change for women and men, respectively. The risk of having changed the diet in the past increased with increasing BMI. The trend of increasing risk was especially obvious in women. The increased risk was preserved when adjusted for socioeconomic and lifestyle factors.

Age was not really a risk factor for dietary change. However, when controlling for other variables, in women only, the age group 55-60 years was associated with an increased risk.

Education was not a risk factor when examined alone, but higher education was an indicator of food habit change both in women and men when adjusted for other variables. Socio-economic status, on the other hand, was not related to past food habit change.

The increased risk among widows and widowers and divorced women compared with married individuals in the separate model did not appear in the mutually adjusted model. Instead a decreased risk was observed among women who had not married. There was still an increased risk among divorced men compared with married men. Women and men not born in Sweden were more likely to have changed their diet in the past. Both men and women who lived alone had an increased risk compared with those living together with others.

Smoking and alcohol habits seemed to be related to dietary change. In women and men, ex-smokers were more likely to be past food habit changers than current smokers. Among men, even non-smokers had an increased risk of having changed the diet. Non-drinkers of alcohol were more likely to be changers than drinkers in both gender groups.

However, physical activity was not clearly related to past food habit change. Females in the highest quartile of physical activity at leisure time were more likely to be diet changers, but the differences between quartiles were small. However, an increasing risk trend $(P=0.03)$ was seen in females with increasing physical activity at leisure time. Men with more than $14 \mathrm{~h}$ of household work per week were more likely to have changed their diet in the past.

In women, BMI and waist circumference were both genuine risk factors for past food habit change when analysed in the same model, but risk estimates became lower. Among men, only BMI was positively associated with increased risk for food habit change, not waist circumference, when analysed in the same model. Waist circumference and BMI were highly correlated in this study, with a Pearson correlation coefficient of 0.87 in women and 0.88 in men.

\section{Reasons for food habit change}

BMI values differed significantly depending on the specific reason for food habit change (Table 4). Individuals reporting health reasons type one only, both types of health reasons, and both health and non-health reasons had the highest BMI values. Individuals in these categories all reported at least one health reason related to the metabolic syndrome. In women, mean BMI in these categories was clearly different from mean BMI in the other reasons categories. In both gender groups, the lowest BMI values were observed among individuals with other health reasons (like allergies) and non-health reasons. The estimates were significantly lower in these categories compared with non-changers. When adjusted for other socio-economic and lifestyle variables (data not shown) these relationships did not change.

In individuals with health reasons type two, the reported change in diet was more distant in the past compared with individuals having other reasons for change.

Respondents who changed food habits a long time ago had lower BMI than respondents who reported a more recent dietary change. Significant trends in BMI were observed across the number of years since change both among women and men reporting diet change due to type one, or a mix between health one and type two health reasons (data not shown).

\section{Discussion}

This study examines obesity status and other characteristics associated with self-reported past food habit change. Overall, individuals who reported a past food habit change are more obese than individuals with no reported change. However, individuals with past food habit change because of health reasons associated with the metabolic syndrome are more obese than individuals with no food habit change or food habit change because of non-health reasons. This study also suggests that high education level, living alone, not born in Sweden and being retired are associated with past food habit change. Moreover, different health-related behaviours are associated with past food habit change, including smoking and alcohol habits.

A similar proportion of men and women reported a past food habit change in the present study, although other studies have observed that women are more willing to change their $\operatorname{diet}^{21}$ and have actually changed their 
Table 2 Risk of past food habit change in a sample of women from the Malmo Diet and cancer cohort

\begin{tabular}{|c|c|c|c|c|c|c|}
\hline & \multicolumn{3}{|c|}{ Separate models } & \multicolumn{3}{|c|}{ Mutually adjusted model ${ }^{*}$} \\
\hline & $n$ & Risk for diet change & $95 \% \mathrm{Cl}$ & $n$ & Risk for diet change & $95 \% \mathrm{Cl}$ \\
\hline \multicolumn{7}{|l|}{ Body mass index $\left(\mathrm{kg} \mathrm{m}^{-2}\right)$} \\
\hline$<25$ & 8003 & 1.00 & - & 7694 & 1.00 & - \\
\hline $25-29$ & 5133 & 1.23 & $1.13-1.33$ & 4884 & 1.18 & $1.08-1.29$ \\
\hline$\geq 30$ & 2112 & 1.65 & $1.48-1.83$ & 1990 & 1.51 & $1.35-1.70$ \\
\hline Test for trend & & & & & & $P<0.001$ \\
\hline \multicolumn{7}{|l|}{ Age (years) } \\
\hline$<50$ & 3853 & 1.00 & - & 3791 & 1.00 & - \\
\hline $50-54$ & 2891 & 1.16 & $1.03-1.30$ & 2795 & 1.09 & $0.97-1.23$ \\
\hline $55-59$ & 2468 & 1.34 & $1.18-1.51$ & 2354 & 1.20 & $1.06-1.37$ \\
\hline $60-64$ & 2678 & 1.43 & $1.27-1.60$ & 2534 & 0.99 & $0.86-1.14$ \\
\hline$\geq 65$ & 3384 & 1.37 & $1.23-1.53$ & 3094 & 0.70 & $0.59-0.84$ \\
\hline Test for trend & & & & & & $P=0.335$ \\
\hline \multicolumn{7}{|l|}{ Education } \\
\hline Elementary & 5948 & 1.00 & - & 5574 & 1.00 & - \\
\hline Primary and secondary & 4629 & 0.95 & $0.87-1.04$ & 4449 & 1.18 & $1.06-1.30$ \\
\hline Upper secondary & 1101 & 1.05 & $0.90-1.22$ & 1074 & 1.24 & $1.05-1.46$ \\
\hline Further education without degree & 1290 & 0.96 & $0.84-1.11$ & 1254 & 1.22 & $1.04-1.43$ \\
\hline University degree & 2269 & 0.99 & $0.88-1.11$ & 2217 & 1.38 & $1.20-1.59$ \\
\hline Test for trend & & & & & & $P=0.001$ \\
\hline \multicolumn{7}{|l|}{ Socio-economic status } \\
\hline Blue-collar worker & 5759 & 1.00 & - & 5459 & 1.00 & - \\
\hline White-collar worker & 8178 & 0.84 & $0.78-0.91$ & 7966 & 0.94 & $0.83-1.05$ \\
\hline Other (self-employed, farmer, etc.) & 1186 & 0.96 & $0.83-1.10$ & 1143 & 1.09 & $0.92-1.28$ \\
\hline \multicolumn{7}{|l|}{ Country of birth } \\
\hline Sweden & 13421 & 1.00 & - & 12854 & 1.00 & - \\
\hline Not in Sweden & 1845 & 1.61 & $1.45-1.79$ & 1714 & 1.36 & $1.21-1.53$ \\
\hline \multicolumn{7}{|l|}{ Occupation } \\
\hline Gainfully employed & 8838 & 1.00 & - & 8700 & 1.00 & - \\
\hline Retired & 5064 & 1.60 & $1.48-1.73$ & 4674 & 1.80 & $1.58-2.05$ \\
\hline Student, home worker or unemployed & 1329 & 1.43 & $1.26-1.63$ & 1194 & 1.37 & $1.18-1.58$ \\
\hline \multicolumn{7}{|l|}{ Marital status } \\
\hline Married & 9162 & 1.00 & - & 8759 & 1.00 & - \\
\hline Non-married & 1414 & 1.04 & $0.91-1.18$ & 1362 & 0.83 & $0.70-0.98$ \\
\hline Divorced & 3115 & 1.33 & $1.21-1.46$ & 3008 & 1.02 & $0.90-1.17$ \\
\hline Widow & 1572 & 1.51 & $1.34-1.70$ & 1439 & 1.05 & $0.89-1.24$ \\
\hline \multicolumn{7}{|l|}{ Co-habitation status } \\
\hline Co-living & 10928 & 1.00 & - & 10482 & 1.00 & - \\
\hline Single living & 4338 & 1.51 & $1.39-1.63$ & 4086 & 1.44 & $1.26-1.65$ \\
\hline \multicolumn{7}{|l|}{ Physical activity at leisure time } \\
\hline Q1 & 3729 & 1.00 & - & 3512 & 1.00 & - \\
\hline Q2 & 3845 & 0.96 & $0.86-1.06$ & 3694 & 1.03 & $0.92-1.15$ \\
\hline Q3 & 3914 & 0.96 & $0.86-1.06$ & 3771 & 1.06 & $0.95-1.30$ \\
\hline Q4 & 3714 & 1.10 & $0.99-1.23$ & 3591 & 1.16 & $1.04-1.30$ \\
\hline Test for trend & & & & & & $P=0.003$ \\
\hline \multicolumn{7}{|l|}{ Physical activity at work } \\
\hline Very low & 6596 & 1.00 & - & 6510 & 1.00 & - \\
\hline Low & 2074 & 1.01 & $0.90-1.13$ & 2027 & 0.95 & $0.84-1.08$ \\
\hline Medium & 4508 & 1.09 & $1.00-1.19$ & 4395 & 0.99 & $0.88-1.11$ \\
\hline High & 1685 & 1.33 & $1.17-1.49$ & 1636 & 1.10 & $0.95-1.28$ \\
\hline Test for trend & & & & & & $P=0.068$ \\
\hline Household work (h week ${ }^{-1}$ ) & & & & & & \\
\hline $0-6$ & 1449 & 1.00 & - & 1387 & 1.00 & - \\
\hline $7-13$ & 3694 & 0.89 & $0.77-1.02$ & 3618 & 0.97 & $0.84-1.13$ \\
\hline $14-19$ & 5345 & 0.90 & $0.78-1.02$ & 5202 & 0.95 & $0.82-1.09$ \\
\hline$\geq 20$ & 4592 & 0.99 & $0.86-1.13$ & 4361 & 0.98 & $0.84-1.13$ \\
\hline Test for trend & & & & & & $P=0.374$ \\
\hline Smoking habit & & & & & & \\
\hline Current smoker & 4340 & 1.00 & - & 4163 & 1.00 & - \\
\hline Ex-smoker & 4291 & 1.29 & $1.17-1.42$ & 4124 & 1.33 & $1.20-1.48$ \\
\hline Non-smoker & 6639 & 1.08 & $0.98-1.18$ & 6281 & 1.04 & $0.94-1.15$ \\
\hline Alcohol consumption & & & & & & \\
\hline Non-drinker & 1171 & 1.00 & - & 1049 & 1.00 & - \\
\hline Low $(<15 \mathrm{~g})$ & 11553 & 0.59 & $0.52-0.67$ & 11031 & 0.65 & $0.57-0.75$ \\
\hline Medium $(15-30 \mathrm{~g})$ & 2179 & 0.39 & $0.33-0.46$ & 2129 & 0.45 & $0.38-0.54$ \\
\hline $\operatorname{High}(>30 \mathrm{~g})$ & 371 & 0.46 & $0.35-0.61$ & 359 & 0.51 & $0.38-0.68$ \\
\hline Test for trend & & & & & & $P<0.001$ \\
\hline
\end{tabular}




\begin{tabular}{|c|c|c|c|c|c|c|}
\hline & \multicolumn{3}{|c|}{ Separate models } & \multicolumn{3}{|c|}{ Mutually adjusted model } \\
\hline & $n$ & Risk for diet change & $95 \% \mathrm{Cl}$ & $n$ & Risk for diet change & $95 \% \mathrm{Cl}$ \\
\hline \multicolumn{7}{|l|}{ Waist } \\
\hline$<80 \mathrm{~cm}$ & 10275 & 1.000 & - & 9881 & 1.000 & - \\
\hline$\geq 80 \mathrm{~cm}$ & 4966 & 1.460 & $1.352-1.577$ & 4679 & $1.201 \dagger$ & $1.071-1.346$ \\
\hline
\end{tabular}

$\mathrm{Cl}$ - confidence interval.

* Adjusted for all listed variables except waist circumference.

† Adjusted for all variables including body mass index.

$\operatorname{diet}^{22,23}$. However, there is an indication that the reasons for change differ between men and women, with men reporting more health reasons type one compared with women. Changing diet because of personal health has been shown to be more important for males ${ }^{23,24}$. In women, cosmetic considerations in relation to obesity may be more important than health reasons for food habit change ${ }^{25}$. The relationships observed with central obesity support this argument. Both general and central obesity predict diet change in women, but it appears that men do not change because of an increasing waist circumference but rather when they have gained more weight in general.

Higher education is associated with increased risk of past food habit change. This may indicate that bettereducated individuals are more aware of the importance of the diet and find it easier to access and understand complex information about diet ${ }^{26}$. High educational level among men has previously been associated with more healthy food habits ${ }^{27}$. However, knowledge of nutrition also tends to increase with socio-economic status ${ }^{26}$, but no increased risk of past food habit change is observed across socio-economic status groups in the present study. Socioeconomic index used herein is the established classification from Statistics Sweden based on data about occupation, working task and position ${ }^{18}$. Education and socio-economic status are often highly correlated but the correlation may vary in different populations. Both education and socio-economic status have previously been associated with a change to healthier food habits ${ }^{28}$. However, another study found the opposite result ${ }^{27}$.

Most studies have only asked for a change towards a healthier diet. Although health reasons clearly dominate, the information collected in the MDC study captures both food habit changes for health and non-health reasons.

When the life situation changes, lifestyle - including food habits - may also change. Living alone is a stronger predictor of past food habit change than being divorced or being a widow or widower. This may indicate that a change of diet is more easily accomplished if not living together with other people, i.e. when other people's preferences do not influence the choice of food ${ }^{29}$. The increased risk among individuals not born in Sweden is expected, because food habits often change when individuals move to another country ${ }^{30}$.
An overall change in awareness of the health importance of other lifestyle factors may be linked to a change in food habits. In this study, change in smoking habits, alcohol habits and dietary habits seem to be related, with more exsmokers and non-drinkers among past food habit changers. Many of the non-drinkers may be ex-drinkers and a change in food habits may also be associated with smoking and drinking cessation. These results are similar to previous observations about health-related behaviour patterns, indicating that many unhealthy behaviours, including smoking, alcohol consumption, physical inactivity and unhealthy dietary habits, often are combined ${ }^{31,32}$. However, in the present study, physical activity does not seem to be strongly connected to past food habit change. We only know the self-reported physical activity at the baseline examination, not if study participants have changed their activity habit in the past. Individuals with past food habit change are more obese and one plausible suggestion might be that those who have changed food habits were less physically active before the change.

The increased risk of past food habit change among obese subjects might be due to dieting behaviour. Dieting is supposed to be more common among females and may be one explanation for the stronger association between obesity and past food habit change in women than in men $^{33}$. However, most subjects did not report obesity as a reason for the change in food habits. Among men and women with past food habit change, 26\% and 30\% respectively reported weight reduction as one reason for the change.

However, there is no information concerning obesity status at the time when the change occurred, which is a limitation of this study. It is possible that some of the respondents already were obese at the time dietary change was instigated, and lost some weight afterwards. Analyses concerning time since change indicate that those individuals who changed their diet a long time ago have lower BMI than individuals who reported a more recent change. The observation was most obvious among respondents giving at least one of the type one health reasons for change. So, for some respondents some weight reduction appears to have occurred.

This study only captures self-reported food habit change, which is a limitation. Also, obesity is often associated with 
Table 3 Risk of past food habit change in a sample of men from the Malmo Diet and Cancer cohort

\begin{tabular}{|c|c|c|c|c|c|c|}
\hline & \multicolumn{3}{|c|}{ Separately adjusted } & \multicolumn{3}{|c|}{ Mutually adjusted* } \\
\hline & $n$ & Risk for diet change & $95 \% \mathrm{Cl}$ & $n$ & Risk for diet change & $95 \% \mathrm{Cl}$ \\
\hline \multicolumn{7}{|l|}{ Body mass index $\left(\mathrm{kg} \mathrm{m}^{-2}\right)$} \\
\hline$<25$ & 3666 & 1.00 & - & 3473 & 1.00 & - \\
\hline $25-29$ & 4892 & 1.10 & $0.99-1.22$ & 4621 & 1.07 & $0.96-1.19$ \\
\hline$\geq 30$ & 1284 & 1.53 & $1.32-1.76$ & 1181 & 1.28 & $1.09-1.50$ \\
\hline Test for trend & & & & & & $P<0.001$ \\
\hline \multicolumn{7}{|l|}{ Age (years) } \\
\hline$<50$ & 925 & 1.00 & - & 875 & 1.00 & - \\
\hline $50-54$ & 2288 & 1.00 & $0.83-1.21$ & 2153 & 0.97 & $0.80-1.19$ \\
\hline $55-59$ & 2012 & 1.15 & $0.94-1.39$ & 1867 & 1.02 & $0.83-1.26$ \\
\hline $60-64$ & 2080 & 1.39 & $1.15-1.68$ & 1950 & 1.04 & $0.84-1.29$ \\
\hline$\geq 65$ & 2550 & 1.34 & $1.12-1.62$ & 2430 & 0.72 & $0.57-0.92$ \\
\hline Test for trend & & & & & & $P=0.257$ \\
\hline \multicolumn{7}{|l|}{ Education } \\
\hline Elementary & 4522 & 1.00 & - & 4213 & 1.00 & - \\
\hline Primary and secondary & 1926 & 0.96 & $0.84-1.09$ & 1815 & 1.07 & $0.92-1.23$ \\
\hline Upper secondary & 1172 & 0.88 & $0.75-1.03$ & 1116 & 0.93 & $0.78-1.12$ \\
\hline Further education without degree & 909 & 1.14 & $0.97-1.35$ & 876 & 1.26 & $1.04-1.52$ \\
\hline University degree & 1301 & 1.11 & $0.96-1.28$ & 1255 & 1.22 & $1.02-1.45$ \\
\hline Test for trend & & & & & & $P=0.029$ \\
\hline \multicolumn{7}{|l|}{ Socio-economic status } \\
\hline Blue-collar worker & 3543 & 1.00 & - & 3306 & 1.00 & - \\
\hline White-collar worker & 4552 & 0.98 & $0.88-1.08$ & 4387 & 1.10 & $0.96-1.27$ \\
\hline Other (self-employed, farmer, etc.) & 1724 & 0.95 & $0.83-1.10$ & 1582 & 1.06 & $0.90-1.25$ \\
\hline \multicolumn{7}{|l|}{ Country of birth } \\
\hline Sweden & 8652 & 1.00 & - & 8182 & 1.00 & - \\
\hline Not in Sweden & 1201 & 1.40 & $1.22-1.60$ & 1093 & 1.29 & $1.11-1.50$ \\
\hline \multicolumn{7}{|l|}{ Occupation } \\
\hline Gainfully employed & 5462 & 1.00 & - & 5150 & 1.00 & - \\
\hline Retired & 3721 & 1.67 & $1.52-1.85$ & 3502 & 1.83 & $1.56-2.15$ \\
\hline Student, home worker or unemployed & 647 & 1.63 & $1.35-1.96$ & 623 & 1.45 & $1.19-1.77$ \\
\hline \multicolumn{7}{|l|}{ Marital status } \\
\hline Married & 7105 & 1.00 & - & 6669 & 1.00 & - \\
\hline Non-married & 1004 & 1.18 & $1.01-1.38$ & 945 & 1.10 & $0.89-1.35$ \\
\hline Divorced & 1408 & 1.34 & $1.17-1.52$ & 1334 & 1.22 & $1.01-1.46$ \\
\hline Widower & 335 & 1.39 & $1.09-1.78$ & 327 & 1.11 & $0.83-1.48$ \\
\hline \multicolumn{7}{|l|}{ Co-habitation status } \\
\hline Co-living & 7989 & 1.00 & - & 7498 & 1.00 & - \\
\hline Single living & 1858 & 1.43 & $1.28-1.61$ & 1777 & 1.26 & $1.04-1.51$ \\
\hline \multicolumn{7}{|l|}{ Physical activity at leisure time } \\
\hline Q1 & 2458 & 1.00 & - & 2233 & 1.00 & - \\
\hline Q2 & 2343 & 0.93 & $0.81-1.07$ & 2232 & 0.95 & $0.82-1.10$ \\
\hline Q3 & 2323 & 0.95 & $0.83-1.09$ & 2237 & 0.96 & $0.83-1.11$ \\
\hline Q4 & 2688 & 1.10 & $0.97-1.26$ & 2573 & 1.04 & $0.91-1.20$ \\
\hline Test for trend & & & & & & $P=0.308$ \\
\hline \multicolumn{7}{|l|}{ Physical activity at work } \\
\hline Very low & 4645 & 1.00 & - & 4428 & 1.00 & - \\
\hline Low & 1067 & 1.09 & $0.93-1.28$ & 1010 & 1.11 & $0.93-1.31$ \\
\hline Medium & 2026 & 1.02 & $0.90-1.15$ & 1925 & 1.01 & $0.88-1.17$ \\
\hline High & 2054 & 1.09 & $0.96-1.23$ & 1912 & 1.08 & $0.92-1.27$ \\
\hline Test for trend & & & & & & $P=0.420$ \\
\hline Household work (h week ${ }^{-1}$ ) & & & & & & \\
\hline $0-6$ & 4903 & 1.00 & - & 4821 & 1.00 & - \\
\hline $7-13$ & 2845 & 1.17 & $1.05-1.31$ & 2806 & 1.07 & $0.95-1.20$ \\
\hline $14-19$ & 1236 & 1.46 & $1.27-1.69$ & 1215 & 1.19 & $1.02-1.40$ \\
\hline$\geq 20$ & 443 & 1.85 & $1.50-2.29$ & 433 & 1.41 & $1.13-1.76$ \\
\hline Test for trend & & & & & & $P<0.001$ \\
\hline Smoking habit & & & & & & \\
\hline Current smoker & 2832 & 1.00 & - & 2635 & 1.00 & - \\
\hline Ex-smoker & 4262 & 1.70 & $1.51-1.91$ & 4021 & 1.76 & $1.55-2.00$ \\
\hline Non-smoker & 2758 & 1.22 & $1.07-1.40$ & 2619 & 1.26 & $1.09-1.46$ \\
\hline Alcohol consumption & & & & & & \\
\hline Non-drinker & 442 & 1.00 & - & 398 & 1.00 & - \\
\hline Low $(<20 \mathrm{~g})$ & 6539 & 0.65 & $0.53-0.80$ & 6153 & 0.70 & $0.56-0.87$ \\
\hline Medium $(20-40 \mathrm{~g})$ & 2131 & 0.51 & $0.41-0.64$ & 2029 & 0.57 & $0.45-0.73$ \\
\hline High $(>40 \mathrm{~g})$ & 743 & 0.53 & $0.41-0.70$ & 695 & 0.57 & $0.42-0.76$ \\
\hline Test for trend & & & & & & $P<0.001$ \\
\hline
\end{tabular}




\begin{tabular}{|c|c|c|c|c|c|c|}
\hline & \multicolumn{3}{|c|}{ Separately adjusted } & \multicolumn{3}{|c|}{ Mutually adjusted } \\
\hline & $n$ & Risk for diet change & $95 \% \mathrm{Cl}$ & $n$ & Risk for diet change & $95 \% \mathrm{Cl}$ \\
\hline \multicolumn{7}{|l|}{ Waist } \\
\hline$<94 \mathrm{~cm}$ & 5585 & 1.000 & - & 5291 & 1.000 & - \\
\hline$\geq 94 \mathrm{~cm}$ & 4251 & 1.182 & $1.075-1.300$ & 3979 & $1.015 \dagger$ & $0.889-1.159$ \\
\hline
\end{tabular}

$\mathrm{Cl}$ - confidence interval.

${ }^{*}$ Adjusted for all listed variables except waist circumference.

† Adjusted for all variables including body mass index.

Table 4 Mean body mass index (BMI) by reason for food habit change in a sample of women (15282) and men (9867) from the Malmo Diet and Cancer cohort

\begin{tabular}{|c|c|c|c|c|c|c|c|}
\hline \multirow[b]{3}{*}{ Reason for past food habit change } & \multirow[b]{3}{*}{$n$} & \multirow[b]{3}{*}{ Mean $\mathrm{BMI}^{\star} \dagger$} & \multirow[b]{3}{*}{$95 \% \mathrm{Cl}$} & \multicolumn{4}{|c|}{ Years since change } \\
\hline & & & & \multicolumn{4}{|c|}{ Percentiles } \\
\hline & & & & 25 & 50 & 75 & 95 \\
\hline \multicolumn{8}{|l|}{ Women } \\
\hline No change & 11542 & $25.0^{\mathrm{b}}$ & $24.9-25.1$ & & & & \\
\hline Health reasons type one & 1181 & $26.3^{\mathrm{c}}$ & $26.1-26.6$ & 1 & 4 & 8 & 21 \\
\hline Health reasons type two & 322 & $23.6^{\mathrm{a}}$ & $23.2-24.0$ & 3 & 8 & 16 & 28 \\
\hline Both types of health reasons & 390 & $26.7^{\mathrm{c}}$ & $26.3-27.1$ & 1 & 4 & 10 & 22 \\
\hline Non-health reasons & 623 & $24.0^{\mathrm{a}}$ & $23.7-24.3$ & 2 & 5 & 11 & 23 \\
\hline Both health and non-health reasons & 1183 & $26.2^{\mathrm{c}}$ & $26.0-26.5$ & 2 & 4 & 9 & 22 \\
\hline \multicolumn{8}{|l|}{ Men } \\
\hline No change & 7613 & $25.9^{\mathrm{b}}$ & $25.8-26.0$ & & & & \\
\hline Health reasons type one & 967 & $26.7^{\mathrm{C}}$ & $26.5-26.9$ & 2 & 5 & 12 & 21 \\
\hline Health reasons type two & 138 & $24.5^{\mathrm{a}}$ & $24.0-25.0$ & 3 & 9 & 15 & 36 \\
\hline Both types of health reasons & 176 & $26.7^{b, c}$ & $26.2-27.2$ & 2 & 5 & 10 & 23 \\
\hline Non-health reasons & 242 & $24.8^{\mathrm{a}}$ & $24.4-25.2$ & 2 & 5 & 13 & 28 \\
\hline Both health and non-health reasons & 693 & $26.8^{\mathrm{c}}$ & $26.5-27.0$ & 2 & 5 & 11 & 22 \\
\hline
\end{tabular}

${ }^{*}$ Age-adjusted.

†Mean values with same superscript letter are not significantly different.

underreporting in studies using self-reported dietary data $^{34}$. Self-reported dietary change in obese individuals may, however, indicate a real change in food habits in an attempt to lose weight, which is restrained eating. It may also indicate an overall change in behaviour patterns including other health behaviours, as indicated by this study. For instance, lifestyle changes, including dietary habits, are common after a cancer diagnosis 35,36 and diagnosis of other diseases ${ }^{37,38}$. Also, the type of dietary change may include either qualitative alterations (e.g. changing type of fats, meats, etc.) and/or quantitative alterations (e.g. reduced energy intake). Dietary changes leading to weight reduction mainly involve quantitative alterations. There are reasons to believe that changes due to metabolic syndrome involve both quantitative changes to lose weight and qualitative changes, e.g. changed balance between macronutrients because of type 2 diabetes ${ }^{39}$. Dietary changes due to allergy etc. probably involve qualitative changes (e.g. replacing ordinary milk for lowlactose milk among individuals with lactose intolerance) ${ }^{40}$. It is also plausible that the perceived dietary change may not always be a real change ${ }^{41}$.
A parallel project examines dietary factors in relation to past food habit change, because we need to know if the quality of the diet differs depending on different reasons for dietary change.

The major importance of the present study lies in the possible confounding of past food habit change on dietdisease relationships. Preliminary analyses within the MDC cohort suggest that women with past food habit change could be at high risk for breast cancer. This could indicate that these women were exposed to dietary and other lifestyle factors associated with increased breast cancer risk preceding the change in dietary habits. So far, studies analysing dietary factors in the MDC study have adjusted analysis for past food habit change ${ }^{42}$. We need to know, however, the specific exposure responsible for an increased disease risk, i.e. to separate the obesity exposure from the dietary exposure. Cancer may have long latency periods, and tumour development proceeds in many steps, including complex metabolic processes that may involve essential nutrients ${ }^{1}$. Dietary habits before a lifestyle change may be positively related to the development of the disease ${ }^{13}$, but the situation may be 
reversed after a change in dietary habits. The availability of data on past food habit change is an advantage of the MDC cohort, which allows researchers to adjust in analysis for an important confounding aspect. Longitudinal studies often repeat the assessment of diet during the follow-up period, in order to capture the long-term dietary exposure during disease-free years, but few other studies request information on past food habit change at baseline.

In summary, past food habit change is associated with obesity and different socio-economic and lifestyle factors. Especially, individuals with reported dietary changes due to reasons related to the metabolic syndrome are more obese compared with other respondents. This study indicates the importance for nutrition epidemiological studies to account for past food habit change when examining relationships between dietary factors and diseases.

\section{Acknowledgements}

The authors wish to acknowledge the funding from the Swedish Cancer Society, the Swedish Medical Research Council, the European Commission and the City of Malmö.

\section{References}

1 World Cancer Research Fund/American Institute for Cancer Research (WCRF/AICR). Food, Nutrition and the Prevention of Cancer: a Global Perspective. London: WCRF/AICR, 1997.

2 Hulshof KF, Brussaard JH, Kruizinga AG, Telman J, Lowik MR. Socio-economic status, dietary intake and $10 \mathrm{y}$ trends: the Dutch National Food Consumption Survey. European Journal of Clinical Nutrition 2003; 57: 128-37.

3 Mulder M, Ranchor AV, Sanderman R, Bouma J, van den Heuvel WJ. The stability of lifestyle behaviour. International Journal of Epidemiology 1998; 27: 199-207.

4 Contento IR, Murphy BM. Psycho-social factors differentiating people who reported making desirable changes in their diets from those who did not. Journal of Nutrition Education 1990; 22: 6-14.

5 Morabia A, Bernstein MS, Heritier S, Beer-Borst S. A Swiss population-based assessment of dietary habits before and after the March 1996 'mad cow disease' crisis. European Journal of Clinical Nutrition 1999; 53: 158-63.

6 Patterson RE, Kristal AR, White E. Do beliefs, knowledge, and perceived norms about diet and cancer predict dietary change? American Journal of Public Health 1996; 86: 1394-400.

7 Harnack LJ, Jeffery RW, Boutelle KN. Temporal trends in energy intake in the United States: an ecologic perspective. American Journal of Clinical Nutrition 2000; 71: 1478-84.

8 Southgate DAT. Dietary change: changing patterns of eating. In: Meiselman HL, MacFie HJH, eds. Food Choice Acceptance and Consumption. London: Blackie Academic \& Professional, 1996; 365-91.

9 Senauer B, Asp E, Kinsey J. Food Trends and the Changing Consumer. St. Paul, MN: Eagan Press, 1991.

10 Edwards JSA, Meiselman HL. Changes in dietary habits during the first year at university. Nutrition Foundation Nutrition Bulletin 2003; 28: 21-34.

11 Wirfalt E, Mattisson I, Gullberg B, Berglund G. Food patterns defined by cluster analysis and their utility as dietary exposure variables: a report from the Malmo Diet and Cancer Study. Public Health Nutrition 2000; 3: 159-73.

12 Key TJ, Schatzkin A, Willett WC, Allen NE, Spencer EA, Travis RC. Diet, nutrition and the prevention of cancer. Public Health Nutrition 2004; 7: 187-200.

13 Hill JO, Melanson EL, Wyatt HT. Dietary fat intake and regulation of energy balance: implications for obesity. Journal of Nutrition 2000; 130: 284S-8S

14 Berglund G, Elmstahl S, Janzon L, Larsson SA. The Malmo Diet and Cancer Study. Design and feasibility. Journal of Internal Medicine 1993; 233: 45-51.

15 Manjer J, Carlsson S, Elmstahl S, Gullberg B, Janzon L, Lindstrom M, et al. The Malmo Diet and Cancer Study: representativity, cancer incidence and mortality in participants and non-participants. European Journal of Cancer Prevention 2001; 10: 489-99.

16 World Health Organization (WHO). Obesity: Preventing and Managing the Global Epidemic. Report of a WHO Consultation. Geneva: WHO, 2000.

17 Lean ME, Han TS, Morrison CE. Waist circumference as a measure for indicating need for weight management. British Medical Journal 1995; 311: 158-61.

18 Statistics Sweden. Occupations in Population and Housing Census 1985 (FoB 1985) According to Nordic Standard Occupation Classification and Swedish Socioeconomic Classification. Stockholm: Statistics Sweden, 1989.

19 Wirfalt E, Mattisson I, Johansson U, Gullberg B, Wallstrom P, Berglund G. A methodological report from the Malmo Diet and Cancer study: development and evaluation of altered routines in dietary data processing. Nutrition Journal 2002; 1: 3 .

20 Royal College of Psychiatrists. Alcohol: Our Favourite Drug. London: Tavistock, 1986.

21 Kristal AR, Hedderson MM, Patterson RE, Neuhouser M, Neuhauser ML. Predictors of self-initiated, healthful dietary change. Journal of the American Dietetic Association 2001; 101: $762-6$.

22 Fagerli RA, Wandel M. Gender differences in opinions and practices with regard to a 'healthy diet'. Appetite 1999; 32: 171-90.

23 Satia JA, Kristal AR, Curry S, Trudeau E. Motivations for healthful dietary change. Public Health Nutrition 2001; 4: 953-9.

24 Hankey CR, Leslie WS, Lean ME. Why lose weight? Reasons for seeking weight loss by overweight but otherwise healthy men. International Journal of Obesity and Related Metabolic Disorders 2002; 26: 880-2.

25 Klem ML, Wing RR, McGuire MT, Seagle HM, Hill JO. A descriptive study of individuals successful at long-term maintenance of substantial weight loss. American Journal of Clinical Nutrition 1997; 66: 239-46.

26 Parmenter K, Waller J, Wardle J. Demographic variation in nutrition knowledge in England. Health Education Research 2000; 15: 163-74

27 Groth MV, Fagt S, Brondsted L. Social determinants of dietary habits in Denmark. European Journal of Clinical Nutrition 2001; 55: 959-66.

28 Lopez-Azpiazu I, Martinez-Gonzalez MA, Leon-Mateos A, Kearney J, Gibney M, Martinez JA. Stages of dietary change and nutrition attitudes in the Spanish population. Public Health 2000; 114: 183-9.

29 Kearney M, Kearney J, Dunne A, Gibney M. Sociodemographic determinants of perceived influences on food choice in a nationally representative sample of Irish adults. Public Health Nutrition 2000; 3: 219-26.

30 Kocturk T. Structure and change in food habits. Scandinavian Journal of Nutrition/Näringsforskning 1996; 40: S108-10.

31 Laaksonen M, Prattala R, Karisto A. Patterns of unhealthy 
behaviour in Finland. European Journal of Public Health 2001; 11: 294-300

32 Berrigan D, Dodd K, Troiano RP, Krebs-Smith SM, Barbash RB. Patterns of health behavior in US adults. Preventive Medicine 2003; 36: 615-23.

33 Wardle J, Johnson F. Weight and dieting: examining levels of weight concern in British adults. International Journal of Obesity and Related Metabolic Disorders 2002; 26: 1144-9.

34 Lissner L. Measuring food intake in studies of obesity. Public Health Nutrition 2002; 5: 889-92.

35 Patterson RE, Neuhouser ML, Hedderson MM, Schwartz SM, Standish LJ, Bowen DJ. Changes in diet, physical activity, and supplement use among adults diagnosed with cancer. Journal of the American Dietetic Association 2003; 103: 323-8.

36 Maskarinec G, Murphy S, Shumay DM, Kakai H. Dietary changes among cancer survivors. European Journal of Cancer Care 2001; 10: 12-20.

37 Newens AJ, McColl E, Bond S. Changes in reported dietary habit and exercise levels after an uncomplicated first myocardial infarction in middle-aged men. Journal of Clinical Nursing 1997; 6: 153-60.

38 Dye CJ, Haley-Zitlin V, Willoughby D. Insights from older adults with type 2 diabetes: making dietary and exercise changes. Diabetes Education 2003; 29: 116-27.

39 Franz MJ, Bantle JP, Beebe CA, Brunzell JD, Chiasson JL, Garg A, et al. Nutrition principles and recommendations in diabetes. Diabetes Care 2004; 27(Suppl. 1): S36-46.

40 Tamm A. Management of lactose intolerance. Scandinavian Journal of Gastroenterology Supplement 1994; 202: 55-63.

41 Arnold MS, Funnell MM, Herman WH, Brown MB, Merritt JH, Fogler JM, et al. Discrepancies between perceived dietary changes and 4-day food records in older adults with diabetes. Journal of the American Dietetic Association 1996; 96: $705-7$.

42 Wirfalt E, Mattisson I, Gullberg B, Johansson U, Olsson H, Berglund G. Postmenopausal breast cancer is associated with high intakes of omega6 fatty acids (Sweden). Cancer Causes \& Control 2002; 13: 883-93. 